\title{
South African and international legislature with relevance to the application of electronic documentation in medicolegal autopsies for practice and research purposes
}

\author{
Salona Prahladh ${ }^{1,2^{*}}$ and Jacqueline Van Wyk ${ }^{3}$
}

\begin{abstract}
Background: Forensic and legal medicine requires all documentation to be recorded in a manner that is admissible in court. Issues surrounding privacy, confidentiality, and security mar the implementation of electronic document systems in medicine. Awareness of current legislature governing record keeping and electronic documentation especially in modern medicine and forensic medicine has not been sufficiently explored. This study explored the current South African and international laws that govern admissibility of evidence, especially relating to electronic evidence, for use in court and research,

Findings: Egypt, UK, Canada and the USA have similar legislation to South Africa regarding admissibility of electronic records. The South African Electronic Communications and Transactions Act no. 25 of 2002 defines data and the Criminal Procedure Act 51 of 1977 further defines the admissibility of evidence in court and the National Health Act regulates publication of deceased information after death.

Conclusions: Forensic medicine requires all documentation to be admissible in court and the storage of data thus requires proper custodianship and a high level of security, which can be achieved with modern technology. Modern medicine is evolving and technology can create secure and efficient methods of record keeping which will benefit forensic and legal medicine. Knowledge of the laws regarding admissibility of evidence can assist in creating electronic evidence that is permitted in court and can be used for research.
\end{abstract}

Keywords: Forensic medicine and pathology, Law, Electronic evidence, Ethics, Rights, Privacy

\section{Background}

Adaptation to a technologically advanced electronic system is the ideal since the early 2000s (Ambinder 2005). The creation of web based systems in medicine such as REDCap (developed in MO, USA), allows researchers to have a secure method to implement and manage online surveys. The software also assists researchers to design

\footnotetext{
*Correspondence: sprahladh@gmail.com

2 Department of Forensic Medicine, Inkosi Albert Luthuli Central Hospital, 1st floor Laboratory Building, 800 Vusi Mzimela Rd., Cato Manor, Durban 4091, South Africa

Full list of author information is available at the end of the article
}

research databases (Mosa et al. 2015). REDCap at Vanderbilt University currently collaborates with approximately 1017 active institutional partners in 79 countries (REDCap Consortium). The software allows the collection, storage and management of the information collected by researchers. Medical departments benefit from an electronic health information system, and the current overhaul of normalcy requires greater use of virtual platforms in the workplace (Mosa et al. 2015; Wilson and Khansa 2018; Khubone et al. 2020; Grange et al. 2020).

Autopsies can be used as an instrument to understand pathological processes of disease and injury and 
provide evidence and data to implement measures for prevention and control. The accumulation of information from death investigation is invaluable for epidemiology, national reporting and statistics and may provide insight and evidence which are fundamental for policy and intervention implementation (Tonder 2013; Burton and Underwood 2007; Kalougivaki 2014; Guze 2015; Rao et al. 2005; Noguchi et al. 2007). The reforms of current data practices in forensic medicine and pathology can provide a valuable platform to address current issues that are related to reporting (Ambinder 2005; Khubone et al. 2020; Guze 2015; Prahladh and van Wyk 2020; Medicine Io 1997; Katurura and Cilliers 2018; MALAYSIA NAO 2011; Nortjie 2017; Kohn 2012; International Standard on Records Management n.d.; Takombe n.d.; Lucas et al. 2019).

\section{Findings}

\section{What laws currently govern autopsies?}

Statutes and regulations relating to death investigation differ depending on the geographical regions of the world. Under the colonial regime, sudden and unnatural deaths were reported for investigation. Coroners were then permitted to conduct an inquiry and investigate the deaths (Koehler 2016). Initially, little or no medical training was required. It then became clear that individuals required training to perform autopsies (Kalougivaki 2014; Koehler 2016; Mao et al. 2020). A potential error during an autopsy examination will be detrimental to an investigation. Persons may be prosecuted with possible false evidence or evidence may be lost resulting in miscarriage of justice (Koehler 2016).

In South Africa, the Inquest Act 59 of 1958 directs the procedures and investigations regarding the inquiry of deaths due to unnatural or unknown causes. Inquests regulate the procedure for medicolegal post mortems into suspicious deaths (Inquests Act 1959). The Regulations of the National Health Act states that only an authorised person (i.e. a qualified forensic pathologist or a medical officer with autopsy training) may conduct a death investigation and medicolegal autopsy (Regulations regarding the rendering of Forensic Pathology Service 2003). The investigation may also include attending the crime scene where the pathologists' may be consulted to provide their expertise on circumstances surrounding the death.

There is an urgent need to rapidly upgrade the current paper record keeping system, which results in missing or empty files, into an electronic system. It should be obligatory to stay abreast with technological development when other medical disciplines have far advanced into this territory, even in resource limited countries (Wilson and Khansa 2018; Grange et al. 2020; Katurura and
Cilliers 2018; Lucas et al. 2019; De Pietro and Francetic 2018; Zayyad and Toycan 2018). Nevertheless, there is a multitude of reasons why this forms a conundrum in forensic medicine just as it does in medicine (Ambinder 2005; Kalougivaki 2014). While patient confidentiality is the most cited reason for not fully embracing an electronic system in Medicine, the system would also need to conform to legislation governing unnatural deaths in forensic medicine (Wilson and Khansa 2018; Medicine Io 1997; Lucas et al. 2019; De Pietro and Francetic 2018). All information collected during an inquest is viewed as being under the authority of the court and magistrate. It is therefore treated with the utmost confidentiality and security. These issues render it necessary to debate how forensic medicine can incorporate an electronic record keeping system that would also be permissible for use in court.

\section{Obtaining evidence for an inquest or death investigation}

The foundation regarding admission of evidence in court is based on the principle that all information that is presented to court, its contents must be proven to be true and incorrigible (Tonder 2013). The Criminal Procedure Act '(CPA) Section 210 conditions that [quotation] "Irrelevant evidence inadmissible ... .." (Criminal Procedure Act 1977). The evidence that is admitted in court must follow the correct legal procedures and therefore must be obtained lawfully, in keeping with section 35(5) of the Constitution of South Africa. Evidence that is procured in lieu of a person's rights as stated by the Bill of Rights should not be presented in court. This evidence will lead to the obstruction or prevention of justice. All conventional evidence must also follow the common law rules as set by precedents. The evidence must conform to the legal rules, and therefore it must be true, authentic, relevant to the matter at hand and as complete as possible.

All evidence obtained during an inquest is subject to the CPA Section 212. "Proof of certain facts by affidavit or ... ... ensure proper custodianship of all documents pertaining to the investigations." (Badiye 2020). Thus when evidence is admitted into a court of law, the statement must be in the form of a sworn affidavit which includes the name and qualifications of the person making the statement. Proof and maintenance of the custodianship of the evidence is important to prevent claims of evidence tampering, as well as alteration or contamination. Detailed records of each person who handles or controls the evidence, including the dates and times of when $\mathrm{s} /$ he received it, are recorded to prevent mishandling of the evidence. The records should also include the person/department to whom the evidence was transferred to. This prevailing chain of evidence must not be 
broken and there should consequently be no gaps during which evidence was unaccounted for or out of the control of a custodian.

\section{Definitions and use of electronic evidence in court}

Current technology has changed how we communicate and share information in our personal and businessrelated interactions. A provision for admissibility issues relating to computer printouts was made in the Civil Proceedings Evidence Act (CPEA) 25 of 1965 (Watney 2009). The CPEA provided that an authenticated computer printout was admissible as evidence of any fact recorded in it. It would be "authenticated" when accompanied by an affidavit and any other additional affidavits that may serve to support the reliability of the printout. The CPEA was applicable to civil proceedings, and thereafter the Law Commission applied for the Act to be used across all criminal proceedings. The CPEA however did not receive widespread approval and was repealed following the enactment of the Electronic Communications and Transactions Act no. 25 of 2002.

The Electronic Communications and Transactions Act (ECTA) no. 25 of 2002 provided a foundation for the authoritative actions regarding the conduct of electronic communications and transactions (No. 25 of 2002: Electronic Communications and Transactions Act 2002). The ECTA was also meant to prevent the abuse of information systems while strengthening the support for the use of electronic communications transactions. It further emphasised the importance of integration of technology and electronic communication into businesses with further development for human resources (No. 25 of 2002: Electronic Communications and Transactions Act 2002).

Chapter 1 of the ECTA defines data as (direct quotation) "data" means electronic representations of information in any form;" and "data message" means data generated sent, received or stored by electronic means and includes-25 (a) voice, where the voice is used in an automated transaction; and (b) a stored record." Additionally, the all-encompassing term of "Digital Evidence" refers to all data or information that is stored on or transmitted by a digital device (Kohn 2012).

When evidence is to be presented in Court, the ECTA states by "(1) In any legal proceedings, the rules of evidence must not be applied so as to deny the admissibility of a data message ... original form." The statement is related to evidence that is in the form of a data message and this evidence cannot be termed to be inadmissible for court due to its form. Thus, creating legal recognition for use of information in an electronic format.

Section 14 (1) of the ECTA provides for a data message to be viewed as an original document if the document can be proven to be true or it can be assessed. It must then also be in a format that it may be displayed in court or it can presented to the appropriate persons for assessment.

With reference to the integrity of the document, Section 14(2) (2) stipulates the computer system must show that the electronic file remained uncorrupted upon retrieval and can be assessed as a true original document. This is necessary since digital technology allows for easy changes to documents that have been scanned into a database. Inspection procedure should therefore explicitly be designed to prevent tampering and corruption of records (Watney 2009). And ultimately, also allow for the auditing of a computer since there are methods to retrieve data even once it is deleted (Ambinder 2005; Mosa et al. 2015).

\section{Data as evidence}

The ECTA has prepared the way to ensure the recognition of electronic data and allows for digital evidence to be treated in a similar manner to traditional paperbased evidence. The resultant application of the definitions and its interpretation in court has led to some confusion among practitioners necessitating a discussion of the Act.

Photographs are traditionally taken as documentary evidence defined in section 33 of the CPEA and are also applicable to criminal proceedings by section 222 of the CPA 51 of 1977 (Civil Proceedings Evidence 1965). Photographs and the device upon which it was stored are consequently considered as documentary evidence for use in court. The manner in which these photographs are obtained or stored is also not stated with clarity within the CPEA or CPA but the normal common law relating to hearsay and admissibility are applicable to them to the same extent as documentary and electronic hearsay. The dependability of an electronic printout thus depends upon the computer and are not excluded from hearsay rules (Lee 2018).

The use of electronic documentation can accordingly be regulated in forensic pathology if it is subjected to rules in line with current South African or International legislation. The use of mobile devices for documentation of evidence may be more challenging especially since cell phones are essentially "mini computers' that may allow for storage and the amendment of documentation and communication. However, and in accordance to the CPA and CPEA, mobile phones can serve as documentary evidence or digital evidence since it can be assessed and audited (Tonder 2013; Criminal Procedure Act 1977; Watney 2009; Civil Proceedings Evidence 1965; Thompson 2013; Goodison et al. 2015; Eoghan Casey 2011). 


\section{The international laws relating to electronic records}

The English law for evidence defines data produced in the absence of human intervention as "real evidence". But data that is dependent on human for production, are subjected to hearsay rules (Lee 2018). Legal interpretations in countries such as South Africa and Canada use the English law of evidence. If the data are regarded as documentary in nature in South Africa, then several statutory exceptions, including those found in the Criminal Justice Act 2003 and the Civil Evidence Act 1995 are applied (Lee 2018).

In Canada, electronic evidence is subject to the same systematic procedure as traditional evidence. The legislation regulating electronic evidence are the Canada Evidence Act, 1985 and the Uniform Electronic Evidence Act, 1999. Canada differs from the Model Law, 1996 (and other jurisdictions) by using the term electronic record instead of data message, digital evidence or computer evidence.

While many legal aspects are interpreted similarly in the USA, the legislation does differ between different states. The USA adopts a business records hearsay exception, and distinguishes between computer-generated records (with no human intervention-real evidence), and computer-stored records (with human intervention or documentary hearsay) (Lee 2018). The admissibility of electronic evidence in the USA is similar to that in South Africa: evidence must be relevant, original and must be the best evidence available that was obtained in a lawful manner (Watney 2009).

In 2004, the Electronic Signature Law no.15/2004 ("E Signature Law") was promulgated in Egypt to regulate the use of the electronic signature (Moustafa Amin SNSLF n.d.). The importance of legislature and regulations regarding electronic documentation in Court is discussed by Amin and Nasreldine (Moustafa Amin SNSLF n.d.). An important judgment, passed in March 2020 in the Egyptian Court of Cassation which relates to disputes involving electronic evidence. It was acknowledged that this can only occur on the ground of forgery as provided in the Egyptian Evidence Law no.25/1968 (Moustafa Amin SNSLF n.d.).

\section{Discussion}

\section{Electronic health records in South Africa}

In 2015, Switzerland passed a federal law requiring health care providers to have interoperable electronic patient records (De Pietro and Francetic 2018). This was to create a platform for information sharing and increase quality of care and efficiency in the health system (De Pietro and Francetic 2018). Switzerland created penalties to help protect against the wrongful disclosure of identifiable health information and further created specialised committees to deal with these aspects (De Pietro and Francetic 2018). Although slow, the law entered into force in 2017.

The National Health Insurance is in the early stages of implementation in South Africa and electronic health records are integral in the process. A multitude of barriers have however been identified to impact on the implementation. The factors include the lack of information technology infrastructure to support the implementation; the need for commitment to user training and processes; the importance of political influence or strategy on its implementation; the necessity of updated legislation and regulations relating to electronic records; and the lack of a framework for implementation and management of electronic health records (Katurura and Cilliers 2018). This is despite many benefits of implementing an e-system as reported in a study in a developing country setting (Mashoka et al. 2019). The involvement of various stakeholders is also integral to the continued and sustained implementation of electronic health records in resource poor settings (Wilson and Khansa 2018; Khubone et al. 2020; Katurura and Cilliers 2018; Mashoka et al. 2019).

\section{Issues regarding the protection of the privacy of the dead}

The laws and constitution of South Africa are clear: $\mathrm{Ch}$ 2, 8 (4) "A juristic person is entitled to the rights in the Bill of Rights ... respected and protected." All persons are protected by the Bill of Rights and all citizens have the right to privacy. This is also reiterated in the Universal Declaration of rights. The Protection of Personal Information Act of 2013 was enacted to protect all persons constitutional rights for protection of personal information ["Purpose of Act ... right of access to information."] (Protection of Personal Information Act 2013). Although the Act has not been fully enacted, parts thereof have been enforced as of July 2020 therefore all persons and businesses have to abide by the regulations set out by the Act (Accountants SAIoC n.d.).

The protection of personal information and the right to dignity is a universal human right, that seemingly extends only to the living. The same respect or dignity is not afforded to the deceased. Laws are created to protect the living and generally the aftermath of death is not considered (Pienaar 2018). There is almost an assumption that the rights and privacy of a person cease once they are no longer living and this issue has repeatedly been argued in courts and academia (Pienaar 2018; Moses and Teja 2018; Murata and Orito 2014). The increased access and use of social media has resulted in the revival of the debated topic of privacy both for the living and the deceased (Murata and Orito 2014). The jurist sees a natural person (human being), other than a juristic person (a trust or a company in law), as having a legal persona. This persona 
is presumed to effectively end after death. Then the deceased has no legal standing and there are no rights or obligations to be protected. From the South African laws currently in place, the disposal of the body of a deceased person is regulated but aspects related to respect and dignity for the dead is not explicitly stated (Pienaar 2018).

\section{Use or publication of deceased's personal information or photos}

The National Health Act of 2003 states (2) "No person shall publish to another person ... such publication granted consent in writing." (National Health Act 2003). The Act provides for the protection of the privacy of the dead with regards to publication or use of information after death. The next of kin of the deceased must be informed and their consent needs to be obtained for permission to publish information regarding the deceased if the permission was not granted prior to death (or in last will and testament). Most health care professionals don't understand the legal and ethical implications of putting patient details on social media such as Whatsapp. Sharing information on social media is an action that should be treated the same manner as publication. It does have the same legal and ethical implications (Bouter et al. 2020). The legal responsibility of the content still falls on the administrator of a social media platform page or chat, even if the content is shared or posted by others. The next of kin may argue that the publication of information/photos relating to the deceased may affect their own dignity indirectly and may show a cause of that effect. Publication of certain facts surrounding the deceased's death may also affect the criminal investigations that may follow an unnatural death.

In forensic pathology, the performance of a medicolegal autopsy and its other related investigations in South Africa is guided by the Inquests Act and similar legislation is enacted in other countries. In this context, the informed consent from the family is not required because the cause of death is of interest to the state, for obtaining justice, and for protecting public health. The body is assigned a unique state mortuary number to ensure confidentiality and chain of evidence and the number is only identifiable to the assigned police officer, family and to the pathologist who performs the autopsy. The information obtained from the autopsies are presented in court and follow the rules for admissibility of evidence (Criminal Procedure Act 1977). Information from autopsies, which can be deidentified, can also be used to benefit public health and to provide evidence for community interventions therefore insight and evidence obtained from autopsies can have a far reaching impact on the community (Tonder 2013; Burton and Underwood 2007;
Kalougivaki 2014; Noguchi et al. 2007; Saladino 1984; Xue et al. 2020).

\section{Integration of technology into forensics and use of electronic information for research}

The premise of Locards principle that whenever there is contact, evidence is left behind holds true in all aspects in our daily lives and can be applied outside of Forensics. The daily use of technology such as computers and cellphones leave a trail of important information that can be used and traced. If this trail of information is continuously audited to maintain credibility, its admissibility in court may not be questioned. It has been shown in low resource settings that the use of electronic and cellphone records have an important positive effect on the accessibility of information (Mashoka et al. 2019). Accessibility to information will create a valuable and hospitable platform that is conducive to research.

The National Health Research Ethics Committee continuously oversees and enforces the norms, standards and best practices required when conducting health research that may involve humans and animals (Africa DoHRoS 2015). It is fundamental that both the risks and benefits of the research are weighed carefully and that Ethics committees should remain alert to ensure that processes and procedures are acceptable, and are fair, and in general beneficial to the public and community (Grange et al. 2020; De Vries and Blockman 2020).

Information obtained from medicolegal investigations can also be used for research following ethical guidelines. The investigations are conducted in accordance with legislature but may also provide important facts and statistics regarding public health and public health concerns (Khubone et al. 2020; Tonder 2013; Katurura and Cilliers 2018; De Vries and Blockman 2020; Fitzek et al. n.d.). The change from paper based to electronic documentation may further improve security and accessibility. Death investigations require a thorough collection of information which may be contributory to implementation of protocols, regulations and improved treatment guidelines (Xue et al. 2020; Fitzek et al. n.d.).

\section{Conclusion}

Technology is rapidly evolving and the challenge remains to keep abreast thereof. The main issues obstructing the implementation of computerised systems in Forensic Medicine remains centred around security, privacy and confidentiality (Medicine Io 1997). Forensic pathology and investigation of unnatural deaths may provide guidance regarding public health issues and it may further gather evidence for 
the formation of legislation, policies, interventions and research (Burton and Underwood 2007; Kalougivaki 2014; Koehler 2016; Saladino 1984). Thus, enabling robustness of this service to deliver the highest quality information possible can be supported with computer or electronic records (Ambinder 2005; Wilson and Khansa 2018; Khubone et al. 2020; Medicine Io 1997; Katurura and Cilliers 2018; MALAYSIA NAO 2011; Nortjie 2017). Despite policy development and vast literature on benefits of electronic health records, security and privacy issues are difficult to overcome even in resource rich countries such as Switzerland (Medicine Io 1997; De Pietro and Francetic 2018). The legal and ethical implications of publication of electronic records are an important consideration as social media becomes a standard method of communication (Tonder 2013; Eoghan Casey 2011; Bouter et al. 2020; Leroux 2004; Fourie 2016). The involvement of various stakeholders is also integral to the continued and sustained implementation of electronic health records in resource poor settings, especially in the implementation of the National Health Insurance in South Africa (Wilson and Khansa 2018; Katurura and Cilliers 2018; Lucas et al. 2019; De Pietro and Francetic 2018; Zayyad and Toycan 2018; Mashoka et al. 2019). Insight driven research supported by the implementation of electronic records have substantial benefits, which include and may not be limited to improving the quality of healthcare service. Insight-driven research is possible since evidence to support and guide policy and legislation ae obtainable. In this way, the use of electronic data for evidence based research can inform policies on issues of public health and effectually decrease costs related to healthcare by preventing or foreseeing serious unintended consequences (Wilson and Khansa 2018; Khubone et al. 2020; Grange et al. 2020; Katurura and Cilliers 2018; Lucas et al. 2019; De Pietro and Francetic 2018; Mashoka et al. 2019).

\section{Abbreviations \\ CPEA: Civil Proceedings Evidence Act 25 of 1965; CPA: Criminal Procedure Act 51 of 1977; SMME: Small, medium, micro enterprises; ECTA: Electronic Communications and Transaction Act 25 of 2002; REDCAP: Research Electronic Data Capture.}

\section{Acknowledgements}

None.

\section{Authors' contributions}

SP conceptualized the report under the supervision of JV. SP prepared the manuscript and $\mathrm{JV}$ reviewed it. The authors read and approved the final manuscript.

\section{Funding}

None
Availability of data and materials

All articles referenced are available online or will be made available by author on request.

\section{Declarations}

Ethics approval and consent to participate

Ethical approval is not required as the article is based on published literature.

\section{Consent for publication}

Not applicable

\section{Competing interests}

All authors declare that they have no competing interests.

\section{Author details}

${ }^{1}$ Kwazulu Natal Department of Health South Africa, University of KwazuluNatal-Nelson Mandela Medical School, Berea, South Africa. ${ }^{2}$ Department of Forensic Medicine, Inkosi Albert Luthuli Central Hospital, 1st floor Laboratory Building, 800 Vusi Mzimela Rd., Cato Manor, Durban 4091, South Africa. ${ }^{3}$ School of Clinical Medicine, College of Health Sciences, University of KwaZulu-Natal, Room 218A, Main Medical School Building Umbilo Campus, Durban, South Africa.

Received: 10 May 2021 Accepted: 12 December 2021

Published online: 03 January 2022

\section{References}

Accountants SAloC. (n.d.) Protection of Personal Information Act https://www. saica.co.za/Technical/LegalandGovernance/Legislation/ProtectionofPer sonallnformationAct/tabid/3335/language/en-ZA/Default.aspx2020 [Available from: https://www.saica.co.za/Technical/LegalandGovernance/ Legislation/ProtectionofPersonallnformationAct/tabid/3335/language/ en-ZA/Default.aspx

Africa DoHRoS. Ethics in Health Research: Principles, Processes and Structure. In: Africa DoHRoS, editor. 2015

Ambinder EP (2005) Electronic health records. J Oncol Pract 1(2):57-63 Badiye AMR (2020) Chain of custody. StatPearls, Treasure Island

Bouter C, Venter B, Etheredge H (2020) Guidelines for the use of WhatsApp groups in clinical settings in South Africa. S Afr Med J 110(5):364-368

Burton JL, Underwood J (2007) Clinical, educational, and epidemiological value of autopsy. Lancet 369(9571):1471-1480

Civil Proceedings Evidence Act 25 of 1965, Stat. Act 25 (1965). https://www. gov.za/documents/acts

Criminal Procedure Act 51 of 1977, (1977). https://www.gov.za/documents/ acts

De Pietro C, Francetic I (2018) E-health in Switzerland: the laborious adoption of the federal law on electronic health records (EHR) and health information exchange (HIE) networks. Health Policy 122(2):69-74

De Vries JTB, Blockman M (2020) Research on COVID-19 in South Africa: guiding principles for informed consent. SAMJ

Eoghan Casey BT (2011) Digital Evidnce on Mobile devices. In: Digital evidence and computer crime [internet] Third. [1-43]

Fitzek A, Sperhake J, Edler C, Schröder AS, Heinemann A, Heinrich F et al Evidence for systematic autopsies in COVID-19 positive deceased: case report of the first German investigated COVID-19 death. Rechtsmedizin (Berl):1-6

Fourie P (2016) Using social media as evidence in south African courts. North West Univeristy

Goodison SE, Davis RC, Jackson BA. Digital evidence and the U.S. criminal justice system: identifying technology and other needs to more effectively acquire and utilize digital evidence RAND Corporation 2015 [Available from: https://www.rand.org/pubs/research_reports/RR890.html

Grange ES, Neil EJ, Stoffel M, Singh AP, Tseng E, Resco-Summers K et al (2020) Responding to COVID-19: the UW medicine information technology services experience. Appl Clin Inform 11(2):265-275

Guze PA (2015) Using technology to meet the challenges of medical education. Trans Am Clin Climatol Assoc 126:260-270 
Inquests Act, Stat. Act 58 of 1959 (1 January 1960, 1959). https://www.gov.za/ documents/acts

International Standard on Records Management, (n.d.) ISO 154893 International Standard on Information and Documentation - Records Management Processes - Metadata for Records, ISO 23081

Kalougivaki J (2014) Medico-legal death investigation systems in the Pacific and creating a stronger Pacific disaster victim identification network. Journal of forensic. Research. 06

Katurura M, Cilliers $L$ (2018) Electronic health record system in the public health care sector of South Africa: a systematic literature review. African J Prim Health Care Fam Med 10

Khubone T, Tlou B, Mashamba-Thompson TP (2020) Electronic health information systems to improve disease diagnosis and Management at Point-ofCare in low and middle income countries: a narrative review. Diagnostics (2075-4418) 10(5):327

Koehler SA (2016) Chapter 7 - death investigation. In: Freeman MD, Zeegers MP (eds) Forensic epidemiology. Academic Press, Amsterdam, pp 179-199

Kohn MD (2012) Integrated digital forensic process model. University of Pretoria

Lee S (2018) An analysis of the regulatory environment governing hearsay electronic evidence in South Africa: suggestions for reform - part one. Potchefstroom Electronic Law J 21(0)

Leroux O (2004) Legal admissibility of electronic evidence. Int Rev Law Comput Technol 18(2):193-220

Lucas B, Schladitz P, Schirrmeister W, Pliske G, Walcher F, Kulla M et al (2019) The way from pen and paper to electronic documentation in a German emergency department. BMC Health Serv Res 19(1):N.PAG

MALAYSIA NAO (2011) Electronic records management systems -system specifications for public offices version 3

Mao D, Zhou N, Zheng D, Yue J, Zhao Q, Luo B et al (2020) Guide to forensic pathology practice for death cases related to coronavirus disease 2019 (COVID-19) (trial draft). Forensic Sci Res 5(1):1-7

Mashoka RJ, Murray B, George U, Lobue N, Mfinanga J, Sawe H et al (2019) Implementation of electronic medical records at an emergency medicine Department in Tanzania: the information technology perspective. African J Emerg Med 9(4):165-171

Medicine lo (1997) The computer-based patient record: an essential technology for health care, revised edition. Dick RS, Steen EB, Detmer DE, editors. The National Academies Press, Washington, DC, p 256

Mosa ASM, Yoo I, Parker JC (2015) Online electronic data capture and research data repository system for clinical and translational research. Mo Med 112(1):46-52

Moses A, Teja PD (2018) The grave issue of privacy of the deceased. Indian Law Public Policy 5(1):1-20

Moustafa Amin SNSLF. (n.d.) The evidentiary weight of electronic documents in light of the Egyptian E-Signature Law No.15/2004 and recent case law https://www.lexology.com/library/detail.aspx?g=c858df08-939e-429b900d-4892d45e177d2020 [Available from: https://www.lexology.com/ library/detail.aspx?g=c858df08-939e-429b-900d-4892d45e177d

Murata K, Orito Y. Privacy after Death 2014

National Health Act, 2003 Regulations Regarding The General Control of Human Bodies, Tissue, Blood, Blood Products and Gametes, (2003). https://www.gov.za/documents/acts

No. 25 of 2002: Electronic Communications and Transactions Act, 2002, (2002)

Noguchi TT, Rogers C, Sathyavagiswaran L (2007) Quality improvement of patient care - forensic pathologists' perspective. Legal Med 9(2):71-75

Nortjie A. Electronically generated evidence used in commercial litigation 2017 [Available from: https://www.schoemanlaw.co.za/electronicallygenerated-evidence-used-commercial-litigation/

Pienaar C (2018) Is it unlawful to treat the dead without respect and dignity? Prof Nurs Today 22(49-51)

Prahladh S, van Wyk J (2020) Protocol for a scoping review of the current data practices in forensic medicine. Syst Rev 9(1):76

Protection of Personal Information Act, 2013, Stat. Act no. 4 of 2013 (2013). https://www.gov.za/documents/acts

Rao C, Lopez AD, Yang G, Begg S, Ma J (2005) Evaluating national cause-ofdeath statistics: principles and application to the case of China. Bull World Health Organ 83(8):618-625

Regulations regarding the rendering of Forensic Pathology Service, (2003)
Saladino AJ (1984) The efficacy of the autopsy in medical quality assurance. Clin Lab Med 4(1):165-184

Takombe MO. (n.d.) The rise of the machines-understanding electronic evidence

Thompson LL (2013) Mobile devices: new challenges for admissibility of electronic evidence. SciTech Lawyer 9(3/4):33

Tonder GP (2013) The admissibility and evidential weight of electronic evidence in south African legal proceedings: a comparative perspective. Univeristy of the Western Cape

Watney M (2009) Admissibility of electronic evidence in criminal proceedings: an outline of the south African legal position. J Inform Law Technol 2009(1)

Wilson K, Khansa L (2018) Migrating to electronic health record systems: a comparative study between the United States and the United Kingdom. Health Policy 122(11):1232-1239

Xue Y, Lai L, Liu C, Niu Y, Zhao J (2020) Perspectives on the death investigation during the COVID-19 pandemic. Forensic Sci Int: Synergy 2:126-128

Zayyad MA, Toycan M (2018) Factors affecting sustainable adoption of e-health technology in developing countries: an exploratory survey of Nigerian hospitals from the perspective of healthcare professionals. PeerJ. 6:e4436-e

\section{Publisher's Note}

Springer Nature remains neutral with regard to jurisdictional claims in published maps and institutional affiliations.

\section{Submit your manuscript to a SpringerOpen ${ }^{\circ}$ journal and benefit from:}

- Convenient online submission

- Rigorous peer review

- Open access: articles freely available online

- High visibility within the field

- Retaining the copyright to your article

Submit your next manuscript at $\boldsymbol{\nabla}$ springeropen.com 